\title{
Correction to: The role of three-dimensional power Doppler hysterosonography (3-DPDS) in distinguishing atypical polypoid adenomyomas (APAs) from other intrauterine tumors: correlation with pathologic findings
}

Konstantinos Kalmantis $^{1} \cdot$ Georgios Daskalakis $^{1} \cdot$ Anysia Semertzidou $^{1}\left(\mathbb{D} \cdot\right.$ Alexandros Rodolakis $^{1}$

Published online: 30 May 2018

(c) Springer-Verlag GmbH Germany, part of Springer Nature 2018

\section{Correction to: Arch Gynecol Obstet (2017) 296:391-396 \\ https://doi.org/10.1007/s00404-017-4436-3}

In the original publication of the article, the first name and last name of the authors were interchanged. The correct names should read as given below:

Konstantinos Kalmantis, Georgios Daskalakis,

Anysia Semertzidou, Alexandros Rodolakis.

The original article can be found online at https://doi.org/10.1007/ s00404-017-4436-3.

Anysia Semertzidou anitasem1@hotmail.com

1 Division of Gynaecological Oncology, First Department of Obstetrics and Gynecology, Alexandra Hospital,

University of Athens, 80, Vas. Sophias Ave, 11528 Athens,

Greece 